\title{
$r=0$ \\ Princípios e conceitos sobre a ética e uma proposta de uso no desenvolvimento de interfaces de Web sites
}

Isolete T. Dzendzik iso@isodz.com.br
José Carlos Becceneri

becce@lac.inpe.br
Mauricio Gonçalves Vieira Ferreira

mauricio@ccs.inpe.br

\begin{abstract}
The Web ethics is tackled in this article as a constant search with the aim of taking interfaces to the users giving the maximum of facilities of use, considering the limitations of knowledge of many users. The attention given to the development of Web sites and the wish of doing a better work, simply in order to benefit the users, represent the necessary authenticity to an ethic activity. So, some considerations about the use of texts, images, art, technique, technologies and engineering are showed as "ethical principles".
\end{abstract}

\section{Resumo}

A ética na Web é abordada neste artigo como uma busca constante de levar até os usuários interfaces que proporcionem o máximo de facilidade de uso considerando as limitações de conhecimento de muitos usuários. A atenção dedicada ao desenvolvimento de Web sites e a vontade de fazer melhor um trabalho simplesmente para que usuários sejam beneficiados representam a autenticidade necessária para uma atividade ética. Assim, algumas considerações sobre o uso de textos, imagens, arte, técnicas, tecnologias e engenharia são mostradas como "princípios éticos".

Palavras-chave: Desenvolvimento de interfaces Web; Ética na Web; Princípios e conceitos sobre a ética.

\section{Introdução}

O presente artigo apresenta um estudo geral sobre a ética e uma proposta para o seu uso no desenvolvimento de interfaces de Web sites.

Não se pretende aqui criar um suposto "código ético", como se vê referente a algumas profissões, segmentos sociais, etc. Com base em alguns princípios e conceitos, pretende-se mostrar algumas observações de onde e como se pode proceder para que os usuários de um Web site possam fazer uso das interfaces com mais clareza, sem que haja um desgaste visual desnecessário ou um desperdício de tempo a procura dos conteúdos buscados.

Muitas vezes os problemas encontrados em um Web site poderiam ser resolvidos com a dedicação de alguns minutos de atenção ao trabalho que está sendo desenvolvido. Um olhar atento ou uma busca de se colocar no lugar de um usuário considerando suas possíveis dificuldades, representam a ética proposta para o desenvolvimento de Web sites.

Uma questão bastante discutida por Web designers é sobre como fazer interfaces com aspecto profissional, criativas, personalizadas e belas e que ao mesmo tempo não causem dificuldades de uso devido a excessos ou exageros de sofisticações. A proposta de um padrão de design poderia representar uma forma de inibição da capacidade V.3 $\mathrm{N}^{\circ} 1$, Maio, 2005 
intelectual e criativa. No entanto, se os profissionais da Web buscarem refletir sobre as dificuldades encontradas pelos usuários e procurar oferecer "possíveis" soluções, pela simples vontade de fazer melhor o trabalho para o qual se propõem, pode-se afirmar que essa busca é ética! A vontade de fazer um trabalho da melhor maneira possível, dentro dos limites de cada projeto é uma questão ética.

A ética, no sentido da palavra, não pode ser ditada ou imposta, pois a ética é uma questão filosófica e não jurídica. Assim, uma consciência ética pode ser entendida como uma busca (idéia de gerúndio, de quem está sempre buscando) em proceder de uma forma com que os outros sejam beneficiados. Ao contrário do direito, onde se começa a ética de Um não termina a ética de Outro!

Uma consideração ética é a consciência de que nem sempre alguns usuários fazem uso de sistemas por uma livre iniciativa como, por exemplo, sistemas bancários, eleitorais, sistemas de compras, cadastros e inscrições on-line diversas. E no desenvolvimento de Web sites questões éticas que podem melhorar uso das interfaces para os usuários leigos, podem melhorar também para usuários experientes.

\section{Conceitos e considerações}

Para que alguns princípios que envolvem o desenvolvimento de Web sites sejam mencionados ou sugeridos, são mostrados a seguir alguns conceitos e considerações sobre a semântica e uso de alguns termos.

\subsection{Princípios}

Segundo o dicionário Aurélio, princípio representa "o momento ou o local em que algo tem origem, a causa primária, um preceito, uma regra".

Um exemplo de princípios ou práticas para o desenvolvimento de Web sites foi apresentado pela IEEE (Instituto de Engenheiros Elétricos e Eletrônicos) em 2001[Isaak 2001]. O IEEE 2001 é um padrão voluntário conhecido como "Práticas recomendadas para a Internet - Engenharia Web, gerenciamento de Web sites e padrões de ciclos de vida de Web sites". O padrão conhecido como IEEE 2001, sobre benefícios e normas de procedimentos para desenvolvimentos de Web sites, incluiu os tipos de informação que devem ser destacadas em todos os Web sites, tal como informações sobre o criador do Web site; URLs (Uniform resourse Locator) e datas de updates etc [Isaak 2001].

$\mathrm{O}$ que se observa é que nem todos os Web sites têm as necessidades sugeridas pelo IEEE 2001, bem como por outros princípios, sejam de design ou de engenharia. Assim como, nem todos os projetos dispõem de recursos (de tempo, de pessoas e financeiros) para que sejam disponibilizadas todas as possíveis soluções para os problemas ou dificuldades de uso de Web sites.

O uso de práticas, princípios e normas para melhorias no desenvolvimento de Web sites é um papel da engenharia, no entanto a ponderação de uso e o discernimento de onde e como fazer uso de práticas, normas e princípios é uma questão de consciência, de maturidade profissional ou de ética [Domingues 2003]. O melhor que se encontra para um projeto pode não ser (e normalmente não é) o melhor para outro. A consciência de onde, como e quando princípios, regras e normas podem ser mais bem aplicados já não é mais uma questão só da engenharia, mas uma questão de consciência ou uma questão ética.

\subsection{O que é a ética}


A ética é o ramo da filosofia que está diretamente ligado à estética e a arte, e ao comportamento humano na busca de fazer melhor (o que quer que se faça), simplesmente pela vontade de fazê-lo [Moore 1998].

Como um ramo da filosofia a ética estuda os costumes e as ações humanas e seus fundamentos:

- Do grego Ethos - donde - ética (consciência, vontade, responsabilidade e liberdade) [Novaes 2003].

- Do latim Mores - donde - moral (consciência, vontade, responsabilidade e liberdade) [Novaes 2003].

Assim, pode-se entender a ética e a moral como um conjunto de costumes e valores provenientes do temperamento e do caráter do indivíduo [Novaes 2003]. Embora a origem das palavras ética e moral tenha o mesmo sentido, as conotações existentes para cada uma delas adquiriram sentidos diferentes, sendo que a moral é utilizada para o exercício do poder despótico (poder autoritário que visa que simplesmente que a vontade de alguém seja cumprida ou entendida como uma lei) e a ética que visa a busca expansão da consciência humana expressa pela vontade do indivíduo ao desempenhar suas atitudes de forma que outras pessoas possam ser beneficiadas [Obry 2003].

A ética se relaciona com outros ramos da filosofia como, por exemplo, a estética e a arte e é um dos ramos da filosofia mais utilizados com outras ciências, podendo ser vista em:

- Ciências biológicas como a medicina, biologia, odontologia, bioquímica.

- Ciências exatas como a robótica, cibernética, engenharia, Internet, Web, e

- Ciências humanas como na administração de negócios, comércio exterior, psicologia, pedagogia etc.

Algumas abordagens sobre a ética são feitas a seguir, sendo considerações que podem ser utilizadas em Web sites como, por exemplo a ética das imagens, dos textos e a autenticidade da ética.

\subsubsection{A ética das imagens}

A ética das imagens na $W e b$ pode ser vista em ilustrações que correspondam à sugestão de um texto, a imagens que sejam associadas a idéias que precisem ser expressas, a textos que precisam de complementos e a distribuição das mesmas nas interfaces de forma que não representem uma perda de tempo ao usuário que espera seu carregamento.

Segundo, Peixoto (in: Novaes 2003) "a ética das imagens é dar tempo e lugar para as coisas. Aquilo que elas precisam para ser. Imagens que procurem respeitar o tempo e o espaço para que as coisas se cristalizem diante dos nossos olhos. Ética é saber atentar para o tempo e o lugar das coisas" [Novaes 2003].

Muito se associa com a falta de ética no uso das imagens na Web, às imagens de conteúdo adulto ou aquelas que são utilizadas sem autorização de quem tem direito autoral sobre a imagem. No entanto, se um site dispõe de conteúdo adulto e logo na home page dispõem de um aviso de que há conteúdo adulto e esse conteúdo não está exposto antes que o usuário tenha opção de desistir, não há nada de antiético nisso. Se um Web designer não usar em seu site uma imagem com direitos autorias por medo de ser punido, ele simplesmente cumpriu a lei e não necessariamente demonstrou uma consciência ética. Por outro lado, se um Web designer não usar sem autorização ou fazer referências ao autor, pelo respeito que tem a um outro profissional, isso representa um procedimento ético, pois a vontade de respeitar a propriedade criativa e intelectual de outrem foi exercida. O uso ético das imagens na Web é fazer com que as imagens correspondam a uma proposta pré-estabelecida de forma que o conteúdo ou os detalhes 
dessa imagem possam informar ao invés de agredir a percepção do usuário ou agredir a propriedade intelectual.

\subsubsection{A Ética dos textos}

Os textos disponíveis na Web apresentam uma discussão que lhes é peculiar devido a veracidade de fatos mostrados em um texto ou a seriedade existente nas fontes que originaram um assunto ou uma reportagem.

Segundo, Wisnik (in: Novaes, 2003) "acostumamos a ler uma reportagem até como sendo mais real do que o real porque ela tem o peso da palavra escrita, que nos parece uma forma acabada da verdade (...) Então, por isso é que se coloca a questão da ética jornalística! Porque todo o trabalho jornalístico se dá em cima de um poder enorme de fazer e desfazer contextos" [Novaes 2003].

A questão da ética jornalística também retrata a questão da ética nos textos gerais disponíveis na Web. Seja de reportagens completas, documentários disponíveis on-line ou simplesmente de pesquisas sobre assuntos diversos. Uma vez que esteja publicado ou disponível, costuma-se acreditar no que está escrito, a usar em fundamentações de outros trabalhos e a disseminar textos sem que haja, algumas vezes, um questionamento sobre a sua seriedade.

A questão ética para um Web designer no momento em que dispõem on-line conteúdos informativos pode ser vista na seleção dos textos utilizada como fundamentação para um novo texto e na busca em escrever ou informar de acordo com a originalidade dos fatos. A consciência de que haverá um crédito ao que se escreve e conseqüentemente uma utilização da informação que está sendo produzida e disponibilizada é uma questão ética.

\subsubsection{A autenticidade da ética}

A consciência ética representa uma certa credibilidade ou um certo diferencial a quem a pratica. Porém, isso leva indivíduos ou classes sociais a fazer uso do termo "ética" em práticas que de ética têm muito pouco ou nada têm. $O$ fato de alguém fazer uma simples leitura sobre o que uma ou outra pessoa considera como procedimentos éticos não gera maturidade ou crescimento pessoal/profissional e muito menos uma consciência ética.

Quando se realiza na vida privada a ética representa uma consciência ou o exercício da vontade de fazer o bem. As "condições de existência" da ética são praticamente nulas quando se refere à ética no exercício de um poder despótico, arbitrário, representado pelas formas de autoridade que não visam o bem comum, mas a obediência à própria vontade (ditaduras, determinadas lideranças, códigos, etc.).

Ética significa a obediência ao que não é obrigatório. Segundo, Obry "Ética é a finalização das leis e o encerramento dos códigos, a fim de alcançar uma percepção sempre mais nítida dos outros, que se torna assim, prioridade dos nossos interesses". (...) "Praticar a ética é, é sentir antes de fazer e renunciar a qualquer objetivo que prejudicaria alguém, sem receber outra recompensa do que a certeza de ter feito o certo. Ao contrário, as leis são feitas para observar, avaliar e condenar os fatos consumados, depois de terem prejudicado os outros" [Obry 2003].

Muito se discute sobre determinados procedimentos e se a pessoa teve ou não teve consciência de um ato praticado. A resposta para tais questões já é intrínseca a sua pergunta, pois uma vez que se adquire uma consciência ética, não se procede de forma contrária (a menos coagido). A consciência ética está relacionada à maturidade de cada indivíduo e uma vez adquirida, passa-se a proceder de acordo com que todos ou um número máximo de pessoas sejam beneficiados. 
Segundo, Ribeiro "Há um velho conflito entre a ética e o código, ou seja, entre a ética e a lei. Para a lei, basta que sejam obedecidas. Mas, para a ética, isso não quer dizer nada. Os códigos de ética, na verdade, são leis disfarçadas, promulgadas por quem não tem poder para legislar. (...) Nenhum código de ética vai fazer uma pessoa ética" [Ribeiro 2004].

Ética e o exercício da vontade de fazer melhor aquilo que se faz pela simples satisfação de beneficiar as pessoas, de uma forma direta ou indireta. É a vontade de fazer o bem, sem esperar nada em troca além da satisfação de ter feito o bem, o melhor, seja no exercício de um trabalho ou em pequenas atividades cotidianas.

\section{3. Ética na Web}

Para que um procedimento seja verdadeiramente ético é necessário que seja proveniente de uma qualidade de consciência de um indivíduo para com outro. Essa qualidade quando resultante da própria consciência, vontade, responsabilidade e liberdade leva a prática do bem. Assim, o exercício da ética presume que haja pelo menos duas pessoas, uma emissora e outra receptora [Moore 1998]. A ética na Web é abordada neste artigo como princípios praticados por um desenvolvedor de Web sites para com os usuários da Web.

A arte, a criatividade e o design em geral são aliados da engenharia e da tecnologia e não obstáculos a estas. Para que isso se torne uma atividade é preciso que haja um tempo e um espaço para que ambas exerçam seu papel, de forma que o resultado deste exercício represente benefícios para o usuário.

$\mathrm{O}$ design representa literalmente o desenho que é apresentado em uma interface. Este desenho é desenvolvido através do uso da arte, da tecnologia, de técnicas de desenvolvimento de texto, de imagens, de aplicações de conhecimentos de programação e de engenharia.

Dentro da filosofia, há situações em que a ética, a estética e a arte são abordadas de forma muito semelhante, e neste trabalho essas abordagens são feitas com o objetivo de "buscar" levar até o usuário o melhor possível dentro dos limites de cada projeto. Assim, são mostradas algumas questões que visam levar aos usuários, Web sites com uma qualidade aceitável independente se esta seja proveniente da arte ou da engenharia, se é uma questão de ética, de estética, de usabilidade ou se todas estas questões é que representam um bom design. A atenção que se dá ao uso das tecnologias, da arte, de técnicas e da engenharia é mostrada neste trabalho como uma questão ética.

Considerando que princípio é onde algo tem sua origem e ética, é a consciência praticada pela vontade de fazer melhor, pode-se então perceber, em páginas Web, a existência de princípios éticos em aspectos que não procurem atribuir culpas ou punições a pessoas, ao design ou a engenharia, mas que representam melhorias para o usuário. Alguns aspectos que precisam de uma atenção maior no desenvolvimento de Web sites são mostrados a seguir.

\subsection{Estrutura de uma interface}

A estrutura deve ser definida no inicio do projeto, pois é a partir desta que se desenvolve o sistema navegacional. No entanto é na hora da elaboração do design que os problemas de algumas estruturas mais aparecem. Uma estrutura pode ajudar ou dificultar a forma de navegação e a compreensão de uma interface. Alguns problemas mais frequientes, provenientes do tipo de estrutura são mostrados a seguir.

- Estrutura de frame: exibindo a própria barra de navegação com uma página de terceiros na janela principal; dando a falsa impressão de que há uma página única na tela, mas na verdade, a tela fica dividida fazendo com que uma ação do 
usuário não seja respondida em todos os pontos da tela e quebrando o princípio fundamental da Web que diz que "para cada janela do navegador, uma única página e um único endereço (URL)" [WsableWeb 2003]; quando há acoplamento de janelas, levando à redução do tamanho do espaço disponível para visualização do conteúdo; quando a estrutura camufla o endereço de uma página no location do navegador, não permitindo que o usuário mantenha o endereço em seus "Favoritos" ou anote para voltar mais tarde [WsableWeb 2003]; quando gera barras de rolagem em pontos estratégicos da página. Estas barras geradas levam o usuário ao uso excessivo do mouse e comprometem a estética do design [WsableWeb 2003]; quando fragmenta uma página, fazendo com que ela apareça sem o arquivo complementar que normalmente é a barra de navegação [Bruce 2002].

- Estrutura de tabelas: onde há excesso de repetição de código prolongando o tempo de carregamento de cada página e dificultando o trabalho do administrador; quando os arquivos estão em muitos níveis de subdiretórios fazendo com que os URLs fiquem muito extensos, dificultando o registro escrito ou a memorização dos mesmos [Baker 2001].

\subsection{Coerência e legibilidade dos textos}

Para que um texto seja coerente, ele precisa ser disposto com uma certa lógica ou uma sequiência planejada de acordo com cada conteúdo. Para ser legível tem que obedecer a algumas regras que facilitam a leitura, como tamanho da fonte, contraste da cor da fonte com a cor do fundo da tela, tipo ou design da fonte.

Problemas provenientes de textos podem ser vistos quando: as cores das fontes têm um tom muito próximo da cor do fundo da tela; o tamanho da fonte é muito pequeno; o tipo da fonte é muito artístico ou serrilhado, fazendo com uma letra se funda com a outra, causando dificuldade de leitura; quando existem ícones ou letrinhas seguindo o cursor do mouse, anulando o objetivo do cursor que é de dar parâmetro ao leitor do ponto onde ele está, no site, e atrapalhando a visão do conteúdo [Baker 2001]; quando as formas de alinhamento não oferecem um parâmetro vertical como o conseguido com os textos justificados ou alinhados à esquerda [Bruce 2002].

É comum em Web sites a exibição de várias frases, que não ocupam a linha toda, centralizadas ou blocos de textos centralizados ou sem justificar. Isso faz com que não haja um ponto inicial de leitura, o que causa uma dificuldade maior para o usuário. Problemas de contraste aparecem principalmente quando são usadas cores que não fazem parte da tabela Web safe (216 cores). As cores que estão fora desta tabela sofrem variações maiores, tanto quando usadas para cor de fundo como quando usadas para cor de fonte. $\mathrm{O}$ contraste visualizado em um tipo de navegador pode diferenciar muito do contraste visualizado em outro. Isso faz com que reduza a precisão no contraste necessário entre cor de fundo e fonte, para que se tenha uma boa legibilidade [WsableWeb 2003], [Baker 2001].

\subsection{Uso de metáfora e termos inadequados para a Web}

Um outro problema muito comum pode ser visto nas abreviações, em misturas desnecessárias de idiomas e em usos inadequados de metáforas, títulos e termos representativos.

- Abreviações: as abreviações são necessárias algumas vezes. No entanto só devem ser usadas quando não há possibilidades de escrever a palavra toda, devido à falta de espaço. O problema das abreviações e que quem faz a leitura 
tende a completar a palavra abreviada de acordo com uma frase ou palavra que vê com mais freqüência.

- Misturas de idiomas: há termos que não fazem parte de um idioma, mas que não têm um substituto preciso para que possa ser substituído. Essa é uma situação em que a mistura de idiomas é aceita. Termos que sejam representativos de situações da Web, quando substituídos podem representar problemas ao invés de soluções. Mas, isso só vale para termos em que a palavra proveniente de outro idioma seja mais usada e defina melhor uma situação. Existe ainda a questão das frases incompletas como, por exemplo, o uso da palavra "home" que significa casa, para expressar "home page" que é a metáfora usada para expressar "Página inicial". O mesmo é observado no uso do "about" sem o complemento da frase, que pode ser "sobre a empresa, sobre o instituto, sobre mim, sobre um produto". Enfim, as frases incompletas podem ser intuitivas para usuários experientes e um enigma para usuários em geral.

Uso inadequado de metáforas e termos representativos: as metáforas podem e devem ser usadas sempre que representarem uma informação de forma mais evidente que sua expressão natural. Uma metáfora pode ser representada pela seguinte equação: $\mathrm{A}=\mathrm{B}$. Quando $\mathrm{A}$, que representa a situação real tiver menos eficácia de comunicação que B, então usa-se B, que é representação de $\mathrm{A}$, dita com outras palavras como, por exemplo, links ao invés de "pontos (imagens ou textos) clicáveis", página ao invés de "lexia" etc. Quando em uma barra de navegação encontra-se o termo "links", o usuário normalmente acessa esperando encontrar uma interface de abertura que indica o endereço de outros domínios. $\mathrm{O}$ problema é quando, para representar esta situação são usadas frases como: hora do lanche, brindes, etc. Termos como estes não representam metáforas e geram frustrações ao usuário que acessa esperando encontrar o que o link sugere.

Estes exemplos mostram que praticamente não há problemas quanto ao uso de metáfora, pois estas representam uma situação real. Alguns problemas podem ser vistos quando as palavras ou frases não representam uma situação real, não são metáforas, mas representam aquilo que um profissional gostaria de dizer e não encontra palavras adequadas.

\subsection{Harmonia na distribuição dos atributos que compõem uma interface}

Uma interface normalmente é composta de textos, imagens e links (e formulários quando são interfaces dinâmicas). As imagens têm o objetivo de ilustrar o que foi dito em um texto e podem ser estáticas ou animadas. As imagens animadas servem para chamar a atenção do usuário para um assunto que mereça destaque naquela página. Os problemas aparecem quando: existe um excesso de imagens em uma interface causando poluição visual, elevando o tempo para exibição e dificultando a mobilidade do usuário de um ponto para outro, devido ao peso da interface; quando se exibem mais de uma animação por página, deixando o usuário confuso sem saber a que dar mais atenção; quando as imagens são usadas sem necessidade, como por exemplo, onde um assunto já fala por si só.

O uso indiscriminado de ícones em links é o maior exemplo de uso desnecessário de imagens. Se há uma frase que explica o que é o conteúdo correspondente aquele link, não há a necessidade de colocar um ícone para ilustrar. A falta de harmonia existe também quando não há padronização da estrutura das interfaces, do uso de cores, fontes e do design em geral; quando há grandes diferenças do modelo de uma interface para outra, dentro do mesmo site, o usuário poderá ficar em dúvida se já saiu ou ainda está no mesmo site [Baker 2001]; quando não há disponível uma barra de navegação (menu) 
para que o usuário possa saber onde está e para onde poderá ir e quando não um caminho de volta quando o sistema de navegação vai além do segundo nível [WsableWeb 2003].

\subsection{Adoção de um tipo de linguagem e/ou tecnologia}

Estudar uma linguagem e fazer uso da mesma, é um procedimento básico de todo Web design ou programador. Porém, quando se desenvolve uma aplicação para a Web, precisam ser levados em consideração alguns cuidados, principalmente quando se usam linguagens do lado do cliente, como JavaScript, CSS, XML, etc. As linguagens do lado cliente dependem dos recursos da máquina do usuário para que o conteúdo de uma interface seja exibido. Por mais que se façam testes antes de publicar um Web site, não há um meio que saber que recursos existem na máquina de cada usuário. Isso só permite que o desenvolvedor tenha probabilidades de design e não certezas de que o conteúdo será visto na íntegra. Alguns problemas decorrentes da linguagem/tecnologia podem ser vistos no uso de:

- FullScreen: o FullScreen (tela cheia) utiliza toda a tela do computador fazendo com que o usuário perca a barra de ferramentas do navegador [Baker 2001].

- Excesso de plug-ins: com tantos recursos para desenvolvimento de páginas $W e b$, não há necessidade de utilizar tecnologias que façam com que o usuário tenha que baixar plug-ins para visualizar o conteúdo de uma interface, ainda mais se esse plug-in tenha poucas perspectivas de ser utilizado para visualização de outros Web sites (algumas exceções são os plug-ins de Java e Flash, que são bastante utilizados).

- Substituição dos atributos originais: a caracterização dos atributos originais das interfaces representam um design personalizado, mas a substituição destes atributos podem gerar algumas duvidas ao invés de facilidades. Alguns exemplos podem ser vistos quando são usados botões de comandos para a navegação ao invés de serem usados para fazer a ativação de páginas dinâmicas [Baker 2001]; quando o sublinhado dos links é retirado etc [WsableWeb 2003].

\subsection{Objetividade}

Dificilmente um usuário entra em um Web site com o objetivo de navegar, somente pelo motivo de ficar clicando em links. Um usuário clica em um link para encontrar o que a frase exposta no link sugere. Alguns problemas de objetividade podem ser vistos em situações como:

- Insuficiência de dados: nas interfaces onde existem alguns dados disponíveis, mas o usuário não tem informações sobre o que eles são, como podem ser usados ou por que estão lá. Essas páginas dão a impressão de que aquele fragmento de conteúdo foi "jogado" e esquecido lá (o link ocupa um lugar nobre na barra de navegação, mas ninguém sabe ao certo qual é o seu objetivo).

- Nas páginas merchandising: onde um link sugere um conteúdo informativo, mas na verdade leva o usuário a propagandas disfarçadas no meio de textos com conteúdo diferente do sugerido no link.

- Nas páginas de abertura sem conteúdo: que fazem com que o usuário acesse uma página de abertura e aí simplesmente tenha que clicar em um link para entrar definitivamente na página. Há situações mais extremas, onde o usuário tem que escolher uma versão, de linguagem ou tecnologia, para entrar na página [WsableWeb 2003]. 
- Nas páginas “Em Construção": onde só há uma mensagem de que algo está "Em Construção", mas não fala o que está sendo construído e nem a data que estará pronto para o usuário voltar à página se tiver interesse pelo assunto.

- Nas informações inúteis: alguns exemplos de informações inúteis, que não proporcionam nada ao usuário e ainda ocupam um lugar de destaque em uma página, representam falta de maturidade por parte do desenvolvedor ou administrador. Essas informações aparecem na forma de contadores de acesso visíveis, algo que só interessa ao administrador do Web site e não ao internauta; na forma de ordens sem objetivo, como por exemplo, "Clique Aqui" ao invés de um link com uma frase referente ao que existirá se o usuário "Clicar" no link; relógios e calendários que não oferecem nenhuma certeza de que os dados da tela estão corretos; informação de resolução etc.

- Na falta de democracia: a falta de democracia é vista em informações de exclusividade ou de restrição tecnológica, como por exemplo, resolução recomendada, navegador recomendado, resolução fora do padrão sem que haja necessidade de fugir do padrão, excesso de plug-ins e até recursos de hardware necessários [Bruce 2002].

- Na falta de critérios de disponibilidade dos assuntos: como, por exemplo, por ordem de importância e quando há vários assuntos com a mesma importância, uma sequiência por ordem alfabética ou de acordo com uma hierarquia referente ao assunto. Isso vale tanto para links, principalmente em menus, como para segmentações de textos e páginas [WsableWeb 2003], [Baker 2001].

\subsection{Peso de cada interface}

As imagens que fazem parte do design de um Web site são carregadas pelo navegador no momento em que um usuário as solicita. Muitas vezes uma imagem fala mais que muitas linhas de texto, portanto, quando bem relacionadas a um texto, elas não são dispensáveis ou inúteis, ao contrário, são um apoio, uma afirmação. Porém, se forem pesadas demais, ao invés de ajudar, elas poderão ser um obstáculo devido à demora do tempo de carregamento. Isso não quer dizer que os usuários tenham que ser privados das imagens de alta resolução, apenas que elas não precisam ser parte integrante do conteúdo, podendo estar dispostas para download em um ou mais tamanhos. Assim como as imagens, o excesso de texto e o excesso de linhas de código em uma página também retardam o tempo de exibição de um conteúdo e levam o usuário ao excesso do uso da barra de rolagem.

\subsection{Canais de comunicação}

Os canais de comunicação como e-mail, formulários de cadastro, chats, listas de discussão, instant message, são recursos que fazem com que se o usuário quiser mais informações do que as disponíveis no site, saberá a quem contatar e de que forma. Esses canais devem estar visíveis em todas as páginas como uma forma de afirmar que alguém é responsável pelas informações disponíveis e poderá oferecer informações adicionais caso o internauta solicite [Baker 2001], [Bruce 2002].

No entanto há situações em que os canais de comunicação são usados de forma excessiva e arbitrária como, por exemplo, os formulários quando aparecem no carregamento de uma interface em forma de caixinhas de alertas que não permitem que o usuário dê seqüência na navegação enquanto não preenche os campos de dados e clica em um botão de envio; quando aparecem no carregamento de uma interface em janelas pop-up; quando ficam em forma de fly sobrepondo o conteúdo da interface. 


\subsection{Na apresentação estética}

A ética é a investigação geral sobre o que é bom [Moore 1998]. É uma busca constante de fazer melhor aquilo que se faz. Filósofos como Ludwig Wittgenstein, Alexander Gottlieb Baumgarten e Friedrich Nietzsche mostravam estudos sobre a ética e a estética como sendo assuntos difíceis de serem separados considerando a ética como uma forma de consciência que busca fazer o melhor e a estética como uma concretização de um bem que foi feito [Moore 1998], [Novaes 2003].

A arte pressupõe uma técnica e a arte eletrônica pressupõe um uso sistemático de técnicas em ferramentas gráficas e de design. Enquanto um Web designer faz uso de técnicas e as aplica em ferramentas, pode-se dizer que se está diante um trabalho técnico. No entanto, o resultado do uso de técnicas, aplicado em ferramentas, pode ser visto como um trabalho artístico e criativo uma vez que com o uso das mesmas técnicas podem-se obter soluções diferentes, características da maturidade de cada profissional [Domingues 2003].

A falta de ética pode ser vista no descaso para com o design expresso em afirmações não embasadas como por exemplo, de que o design atrapalha o bom funcionamento, mas sem mostrar onde e como atrapalha; quando se vende idéias de simplicidade como se fossem soluções para o design de interfaces, ao invés de buscar uma nova solução estética para cada domínio; quando se ignora que o usuário vê e entende a estética e nem sempre aceita o simples, comum, popular, quando este simples não representa uma bela estética.

\section{Conclusão}

A ética das interfaces $W e b$ pode ser vista tanto em detalhes funcionais como na busca de uma estética mais atraente, dando ao design um tempo e um espaço para que se concretize sem comprometer a funcionalidade e a compreensão do conteúdo como um todo.

As redes globais de computadores dissolveram os limites geográficos. Uma sociedade interconectada eletronicamente e sem fronteiras é uma experiência relativamente nova que desafia as formas legais de diferentes países e de comunidades locais. Os problemas éticos e jurídicos são muito grandes e permanecem ainda amplamente insolúveis, pois necessitam de uma nova cultura, novas práticas e novas leis. E mesmo quando novas leis surgirem, servirão somente para julgar fatos onde tenha existido um agressor e uma vítima.

A falta de ética pode ser praticada não deliberadamente, mas devido a limitações tecnológicas ou inexperiência de profissionais que passam a exercer atividades de desenvolvimento de Web sites pelo simples fato de terem aprendido a usar uma ferramenta de desenvolvimento e não porque tenham adquirido qualificação profissional.

O que precisa ser considerado pelos profissionais da Web é que nem sempre alguns usuários fazem uso de sistemas por iniciativa própria como, por exemplo, sistemas bancários, eleitorais, sistemas de compras, cadastros e inscrições on-line diversas.

As interfaces Web são desenvolvidas para os usuários e usuários vêem e entendem o design, a arte. Conseqüentemente, é nas interfaces onde se encontra a necessidade de se ter mais cuidado com a forma e com a estética dos conteúdos disponíveis aos usuários. Para o usuário não importa se a qualidade é proveniente da arte ou da engenharia; se é uma questão de ética, de estética, ou de usabilidade ou se todas estas questões é que representam um bom design. 
Uma forma de conclusão de um estudo sobre a ética pode ser representada pela "não conclusão", mas como um início, com a idéia de gerúndio, onde há sempre mais a ser acrescentado e por isso se inicia e se renova constantemente, na Web e na vida.

\section{Referências bibliográficas}

BAKER, A. (2001) “Theory”, http://www.merges.net/theory/.

BRUCE R. S. (2002) "The Interspace: Concept Navigation Across Distributed Communities", Computer (IEEE), p. 54-62.

DOMINGUES, D. "Arte e vida no século XXI: tecnologia, arte e criatividade”. São Paulo: Editora UNESP, 2003.

ISAAK, J. "Web Site Engineering Best Practice standards (IEEE 2001)". Fourth International Workshop on Web Site Evolution (WSE'02). Montréal, Canada, October, 2002.

MOORE, G. "Principia Ethica", (1998)

http://www.rbjones.com/rbjpub/philos/bibliog/moore03.htm.

NOVAES, A. "Ética”. São Paulo: 9. ed. Companhia das letras. 2003.

OBRY, J. "Brasil meu amor”. Salvador: BeOne Network, 2003.

RIBEIRO, R. J. (2004) "Códigos de ética", http://noticias.aol.com.br/colunistas/renato_janine/2004/0030.adp.

UsableWeb, portal. (2003) "Usable Web: to many links about Web usability", http://usableweb.org. 